\title{
An analysis of the UCF Optics Ph.D. curriculum
}

\section{David Hagan}

David J. Hagan, "An analysis of the UCF Optics Ph.D. curriculum," Proc. SPIE 9664, Ninth International Topical Meeting on Education and Training in Optics and Photonics, 96640T (24 October 2005); doi: 10.1117/12.2207717

Event: Ninth International Topical Meeting on Education and Training in Optics and Photonics, 2005, Marseille, France 
Ref ETOP056

\title{
An Analysis of the UCF Optics Ph.D. Curriculum
}

David J. Hagan

College of Optics and Photonics: CREOL \& FPCE, University of Central Florida, Orlando, FL 32816-2700, USA

\begin{abstract}
Graduate degrees specializing in optics have been offered at the University of Central Florida since 1987, with stand-alone Optics degrees being offered since 1998. In 2002, the Optics $\mathrm{Ph}$.D. core was radically changed to allow students to take the PhD qualifying examination earlier in their studies, while still providing a broad and rigorous grounding in optics. This involved the creation of several new courses. We describe how this new system has worked over the first three years. We also discuss results of a study on how well typical admission criteria such as GRE exam results, grade point average, etc. predict student performance in our program.
\end{abstract}

\section{Key Words}

Optics, Education, Graduate Education.

\section{Summary}

\section{Background}

The faculty of the Center for Research and Education in Optics and Lasers (CREOL) at the University of Central Florida (UCF) have been actively involved in Graduate education in Optics since 1987. In the early years, students studied in Optics tracks in the Electrical Engineering (EE) and Physics graduate programs, but in 1998, the School of Optics was formed out of the CREOL faculty with its own graduate degree. In 2004 the School became a College, and as of fall, 2005 over 130 graduate optics students are enrolled in its MS and PhD optics degrees. Additionally, approximately 20 graduate students from other programs are working on theses and dissertations with CREOL faculty as their advisors. 


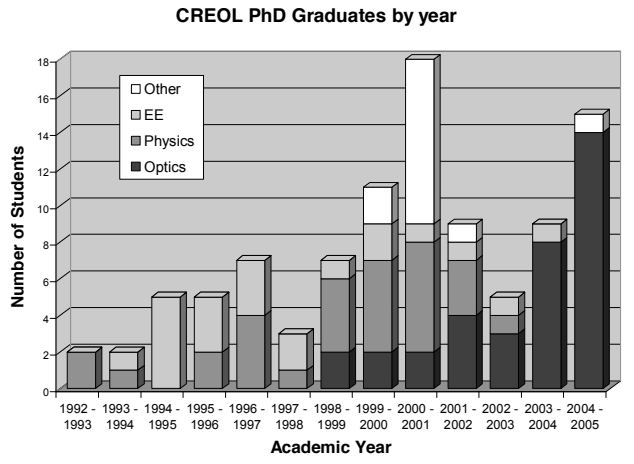

Figure 1. Number of PhD graduates with dissertations supervised by CREOL faculty for each academic year.

Since 1987, a total of $116 \mathrm{PhD}$ students have graduated under CREOL faculty. The rate of doctoral graduations per year, along with their academic degrees is charted in Fig. 1. The dip in 2002-2004 is partly due to the large number of students who elected to leave without PhDs for jobs in industry at the peak of the telecom boom in 1999-2001. It is noticeable that since the $\mathrm{PhD}$ in Optics became available in 1998, most students coming to UCF to study optics have chosen this option over tracks in Physics or EE.

In Fig. 2, we chart the rate of graduation of MS students versus year. It can be noticed that the same trend toward the optics MS program is seen. This is not surprising, since most of the Optics MS degrees are non-thesis and are obtained en-rout to the PhD. Approximately $2 / 3$ of graduates take employment in industry while $1 / 3$ find academic positions (including postdoctoral positions.)

Recently, core courses and other popular graduate optics classes have been offered to students at remote locations via streaming internet web cast. This allows for both synchronous and asynchronous instruction and involves minimal disruption to our students on the main campus taking live classes. Currently approximately $10 \%$ of our course enrollment is to distance education students. 
CREOL MS Graduates by Year

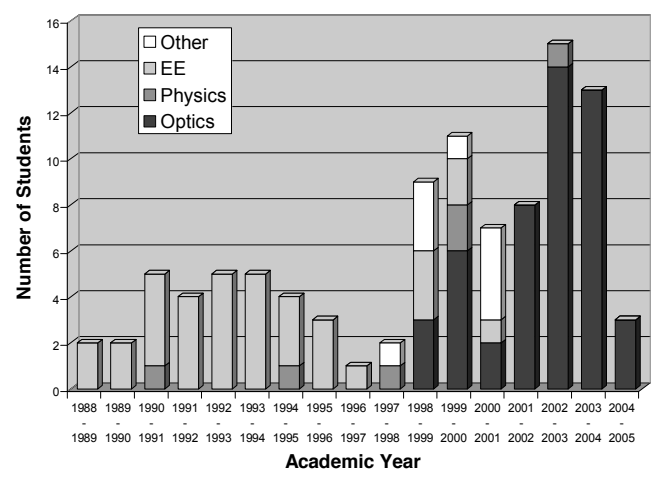

Figure 2. Number of MS graduates versus academic year. Here Optics MS includes both thesis and non-thesis options, but the other disciplines only include those where the thesis was supervised by a CREOL faculty member.

\section{PhD Core}

\begin{tabular}{|l|l|}
\hline \multicolumn{2}{|l|}{ Table 1: PhD Optics Core Courses } \\
\hline New Core & Previous Core \\
\hline Optical wave Propagation & Optical wave Propagation \\
\hline $\begin{array}{l}\text { Interference, Diffraction and } \\
\text { Coherence }\end{array}$ & $\begin{array}{l}\text { Interference, Diffraction } \\
\text { and Coherence }\end{array}$ \\
\hline $\begin{array}{l}\text { Fundamentals of Applied } \\
\text { Optics }\end{array}$ & Radiometry and Detection \\
\hline $\begin{array}{l}\text { Fundamentals of Optical } \\
\text { Science }\end{array}$ & Fourier Optics \\
\hline Fundamentals of Photonics & Geometric Optics \\
\hline & $\begin{array}{l}\text { Optical Properties of } \\
\text { Materials }\end{array}$ \\
\hline & Electro Optics \\
\hline & Laser Engineering \\
\hline
\end{tabular}

In an effort to streamline the $\mathrm{PhD}$ process, in 2002, the Optics $\mathrm{PhD}$ core was changed considerably. The goal was to allow students to take the crucial PhD qualifying examination earlier, yet still maintain a broad and thorough core curriculum in Optics. The courses developed for the new core are shown in Table 1, along with the previous core. While the new core is shorter, it should be noted that all the important elements of the previous core are included in the new core courses. Additionally, the overall optics course requirement of the PhD remained at a minimum of 30 semester credit hours, so that graduates emerge from the new system with no less training in optics. Core courses are taught twice per year to keep class 
sizes small and accommodate students who arrive in the spring. The net result of this has been to allow top students to more rapidly commence their PhD dissertation work, while still providing a thorough optics core and a challenging PhD qualifying exam. The added benefit is that those who do not pass the qualifying exam are usually able to graduate with the MS degree in less than 2 years since enrolling.

\section{Usefulness of Admissions Criteria}

Approximately $50 \%$ of our students are international and additionally, graduate optics students come from diverse academic backgrounds. Hence it is often difficult to find accurate means of assessing applicants to our graduate program. Traditionally, reliance is placed on GRE scores, in particular, the GRE "Quantitative" $(Q)$ score. It is therefore of interest to us to examine how well this score predicts performance in our program. Our results in this respect are mixed. In Table 2, we show the average, minimum and maximum quantitative scores for students who passed the qualifying exam at the $1^{\text {st }}$ attempt, at the $2^{\text {nd }}$ attempt, and for those who ultimately failed. We also show the mean core grade point average (GPA) for students in each category. The mean scores indicate a clear correlation between the $Q$ score and success in our program, but the max and $\min Q$ scores indicate the difficulty with using these scores as absolute admission criteria.

\begin{tabular}{|l|l|l|l|l|}
\hline Table 2 & $\begin{array}{l}\text { Mean } \\
\text { GRE } \\
\text { score }\end{array}$ & $\begin{array}{l}\text { Max GRE } \\
\text { Q score }\end{array}$ & $\begin{array}{l}\text { Min GRE } \\
\text { Q-score }\end{array}$ & $\begin{array}{l}\text { GPA } \\
\left(\begin{array}{l}4.0 \\
\text { scale) }\end{array}\right.\end{array}$ \\
\hline $\begin{array}{l}\text { Passed Qual 1 } \\
\text { time }\end{array}$ & 752 & 800 & 620 & 3.7 \\
\hline $\begin{array}{l}\text { Passed Qual 2 } \\
\text { time }\end{array}$ & 722 & 800 & 640 & 3.4 \\
\hline $\begin{array}{l}\text { Failed Qual } \\
\text { Exam }\end{array}$ & 714 & 790 & 620 & 3.1 \\
\hline
\end{tabular}

Another measure of performance in the program is the time taken for a student to graduate. As seen in Fig. 3, those scoring over 760 show somewhat shorter times to graduate than those with lower scores. However, time-to-graduation is not a conclusive factor in determining quality. Overall, we can conclude that the GRE quantitative score is a useful parameter in determining an applicant's potential for success in the $\mathrm{PhD}$ program, but it cannot be used in isolation to reach an admission decision. 


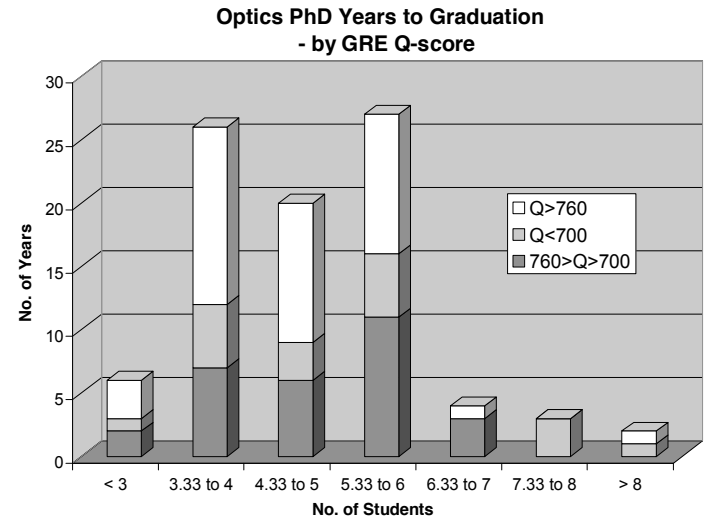

Figure 3. Chart of Time taken to graduate from PhD program for various GRE quantitative score ranges

\section{Future Directions}

In addition to our traditional graduate degrees, we are embarking on a new Photonics Track in the UCF Electrical Engineering (EE) MS program. This is aimed at EE students who have an interest in optics, but wish to pursue their graduate education in engineering. Currently, the College teaches undergraduate optics courses in UCF's Physics and EE undergraduate programs and the possibility of a Bachelors Degree in Optics is being explored.

\section{Acknowledgements}

The author wishes to thank D. Haefner and D. Xavier for compiling data for this paper. 